\title{
Cultural Theory of Poverty and Informal Sector: A Comparison of Street Vendors in Vijayawada and Chennai
}

\section{Shweta Sharma}

Doctoral Researcher, Sheffield University Management School, University of Sheffield S10 3ED, UK.

Type of Review: Peer Reviewed.

DOl: http://dx.doi.org/10.21013/jmss.v13.n2.p2

\section{How to cite this paper:}

Sharma, S. (2018). Cultural Theory of Poverty and Informal Sector: A Comparison of Street Vendors in Vijayawada and Chennai. IRA-International Journal of Management \& Social Sciences (ISSN 2455-2267), 13(2), 32-47. doi:http://dx.doi.org/10.21013/jmss.v13.n2.p2

(C) Institute of Research Advances.

\section{(cc) EY-NO}

This work is licensed under a Creative Commons Attribution-Non Commercial 4.0 International License subject to proper citation to the publication source of the work.

Disclaimer: The scholarly papers as reviewed and published by the Institute of Research Advances (IRA) are the views and opinions of their respective authors and are not the views or opinions of the IRA. The IRA disclaims of any harm or loss caused due to the published content to any party.

Institute of Research Advances is an institutional publisher member of Publishers International Linking Association Inc. (PILA-CrossRef), USA. The institute is an institutional signatory to the Budapest Open Access Initiative, Hungary advocating the open access of scientific and scholarly knowledge. The Institute is a registered content provider under Open Access Initiative Protocol for Metadata Harvesting (OAI-PMH).

The journal is indexed \& included in WorldCat Discovery Service (USA), CrossRef Metadata Search (USA), WorldCat (USA), OCLC (USA), Open J-Gate (India), EZB (Germany) Scilit (Switzerland), Airiti (China), Bielefeld Academic Search Engine (BASE) of Bielefeld University, Germany, PKP Index of Simon Fraser University, Canada. 
IRA-International Journal of Management छ' Social Sciences

\begin{abstract}
The low incomes of poor have been attributed to either their individual factors (such as genetic or their personal choices) or to the socio-cultural factors. This paper is an attempt to understand whether the cultural theory and its associated parameters are equally applicable to different sizes of cities (differentiated by their population sizes). The socio-cultural factors chosen for the study are fourfold: social factors (gender, religion, dependents, choice of occupation and choice of migration), economic factors (occupation before migration), cyclical factors (willingness to stay in the same occupation) and geographical factors (distance of vendors' native place to Chennai/ Vijayawada). Impact of these factors has been tested on income in the two cities (Tier X \{larger\}-Chennai and Tier $Y$ \{smaller\}-Vijayawada) through a Structural Equation Model (SEM). The results reveal that in both the smaller size city (Vijayawada) as well as the larger size city (Chennai) cyclical and economic factors have a major impact on the earnings of vendors. Geographical factors have the least bearing on the income in both the cities. Although social factors are not important in case of Vijayawada, few social factors such as gender, choice of occupation and choice of migration do impact earnings of vendors in Chennai.
\end{abstract}

Keywords: Chennai, Vijayawada, Street Vendors, Structural Equation Model (SEM), Cultural Poverty, Path Co-efficient, Income.

\title{
Introduction
}

Two broad theories have been propagated by scholars over a period - The individual theory of poverty and Cultural theory of poverty. The individual theory of poverty pins the reason for poverty on two main factors: genetic or individual choices. The cultural theory of poverty, on the other hand, incorporates factors such as society, political setting, geographical location, economic conditions and cyclical factors to be mainly responsible for the citizens of a country to be rich or poor [3] [1]. While the first set of theories study the individual in seclusion, the second set of theories hold the socio-cultural setting/ milieu of an individual to be responsible for his/ her poverty [2]. This research tests the second set of theory pertaining to poverty; the cultural theory; on the street vendors of two cities, a Tier X city (Chennai: population of 46,81,087) and a Tier Y city (Vijayawada: population of 10,48,240). The cities have been classified into three categories $(\mathrm{X}: \geq 50,00,000$ population, $\mathrm{Y}: 5,00,000-50,00,000$ population and $\mathrm{Z}: \leq$ $5,00,000$ population) on the basis of population by the Government of India. The cultural theory of poverty has been further subdivided into various sub theories of poverty, viz. the cultural belief systems supporting sub-cultures of poverty, economic, political and social distortions or discrimination leading to poverty and geographical disparities or cumulative and cyclical interdependencies being responsible for poverty of people. The dummy parameters for the cultural theory have been chosen as gender (male or female), number of dependents, religion (Christian, Muslim or Hindu), occupation before migration (not working, service, agriculture, business, vending), choice of occupation (society pressure, family pressure, family business, own choice) as vending and choice of migration (pressure from acquaintance, pressure from relatives, pressure from family members and own choice) from their native place to the Vijayawada. Although gender seems to be a genetic factor and religion seems to be an individual factor at first instance, yet due to the stringent laws in India, an individual does not have an option to choose gender and religion is more or less decided by the family a person is born in rather than his/ her personal choice in India. Thus these two factors have been specifically chosen to be social factor than either genetic or individual factor in the study. Willingness to stay (no or yes) in same occupation of vending has been chosen as a proxy variable for cyclical theory of poverty where a weak economy with lack of opportunities for vendors compels them to opt for the same occupation over an extended period of time. Distance of migration (Chennai: above $800 \mathrm{kms}, 600-800 \mathrm{kms}, 400-600$ kms, 200-400 kms and 0-200 kms and Vijayawada: above $2200 \mathrm{kms}, 1650-2200 \mathrm{kms}, 1100-1650 \mathrm{kms}, 550-1100$ $\mathrm{kms}$ and $0-550 \mathrm{kms}$ ) is a proxy variable for geographical theory of migration where locations far off from the major city suffer more and thus have a bearing on migration of vendors and their earning patterns. The research explores whether the cultural theory is more applicable to both Tier X and Tier Y cities equally or more applicable to either of the two tier of cities. This comparison has been done with the results obtained from research published on cultural theory of poverty applied to Chennai (Tier X city) by the author [5].

\section{Objective and Research Questions}

The objective of this paper is to examine how the set of cultural factors affect the earnings of vendors. These cultural factors can be either social processes, geographical processes or economic processes responsible for low earnings of 
street vendors in two different class of cities differentiated by their population. The research questions framed to explore this theory are as follows:

a) How do the social factors (gender, religion, dependents, choice of occupation and choice of migration) impact income of street vendors in Tier $\mathrm{X}$ and Tier $\mathrm{Y}$ cities?

b) What is the impact of economic factors (occupation before migration) on income of street vendors in Tier $\mathrm{X}$ and Tier Y cities?

c) What is the impact of cyclical factors (willingness to stay in the same occupation) on income of street vendors in in Tier $\mathrm{X}$ and Tier $\mathrm{Y}$ cities?

d) What role do geographical factors (distance of vendors' native place to Chennai/ Vijayawada) play on income of street vendors in Tier $\mathrm{X}$ and Tier $\mathrm{Y}$ cities?

e) Which of the cultural factors (social, cyclical and geographical) play more important role in influencing the income of street vendors in Tier $\mathrm{X}$ and Tier Y cities?

\section{Case Areas - Vijayawada and Chennai}

The study area for the research in Tier X city; Chennai, is Pondy Bazar inT.Nagar(Kodambakkam Zone X, Thyagaraya Nagar Ward 136). The survey for the research was done for street vendors spread over Sivagnanam Street $(0.31 \mathrm{~km})$,Sivaprakasam Street $(0.33 \mathrm{~km})$ and Sir Thyagaraya Road $(1 \mathrm{~km})$ in Pondy Bazar (Fig. 1 (a), (b)).
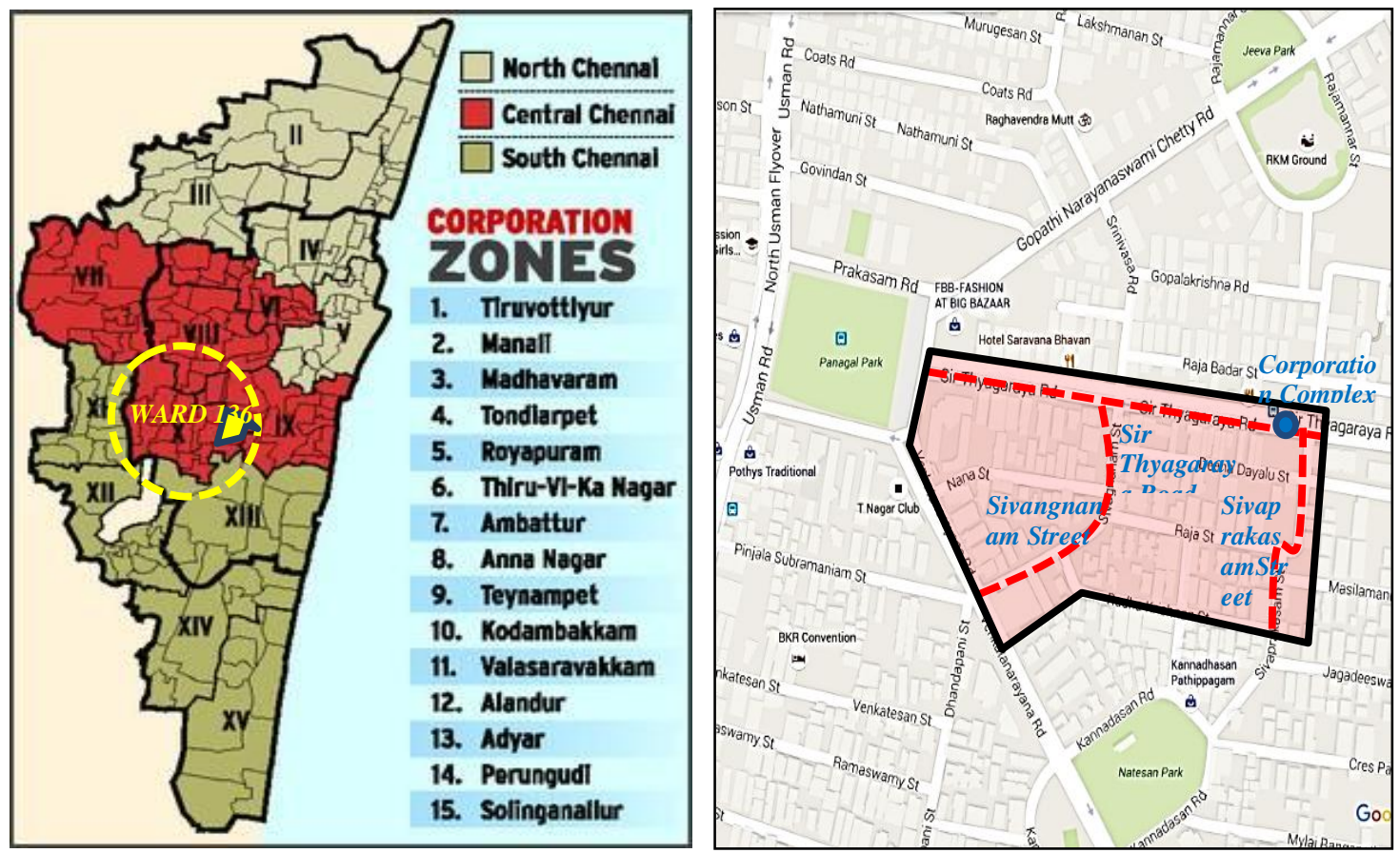

Fig. 1. (a) Location of Pondy bazar in ward; (b)Pondy bazaar boundary \& streets surveyed

Source: Sharma 2018 Although Vijayawada has 12 major locations of vending markets, yet Besant Rad has been chosen as the market for survey of street vendors (Fig. 2). 


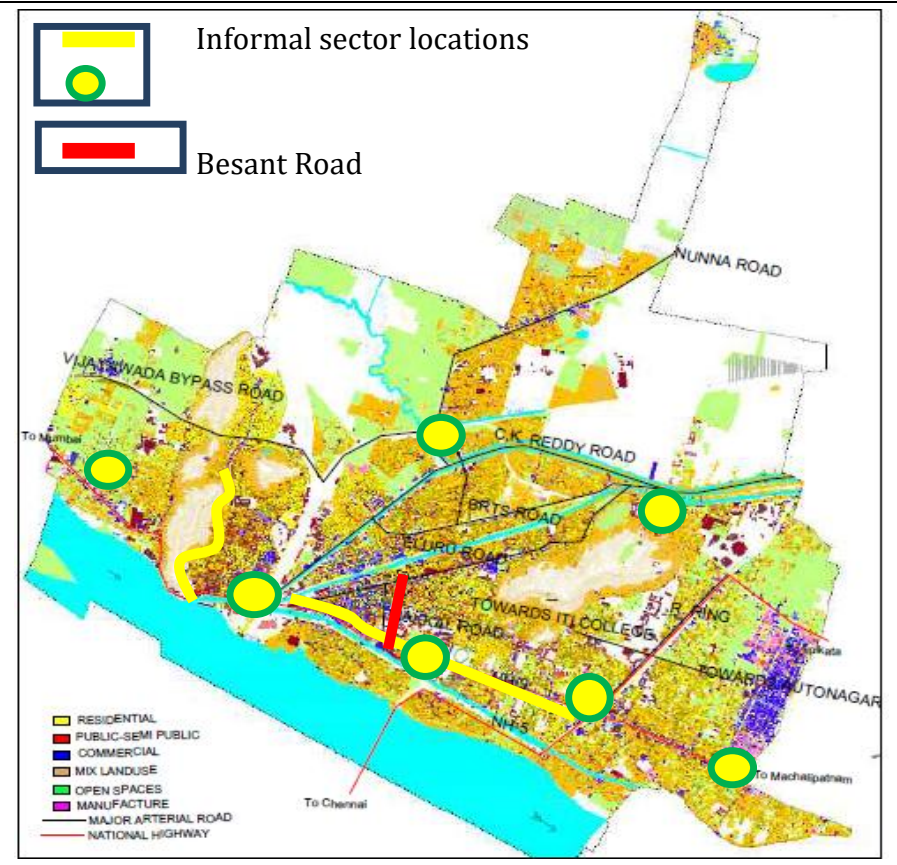

Fig. 2: Street vendor locations in Vijayawada

Source: Sharma 2017

It is a fairly new market (compared to old CBD: One Town), yet attracts clientele because of the diversity of products available in the market and the ease of entry to this market place. Modernity of the market was the main criteria in choosing the survey location in both the cities to maintain uniformity in comparison of results.

\section{Methodology}

\section{Participants}

100 samples were collected from Pondy bazaar street vendors (out of 240 registered vendors in Pondy Bazaar). Another 100 street vendor samples were collected form Besant road in Vijayawada (out of 295 registered vendors in Besant Road). Only registered vendors were chosen for the study. Stratified sampling was used to collect the samples wherein equal number of samples was drawn from men and women alike (50\% each cohort).

\section{Data collection and analysis}

The data was collected from both primary as well as secondary sources. Secondary sources of government publications were used to collect data regarding location map of vendors and their registration details in Chennai and Vijayawada city. Face to face questionnaire method was used to collect primary data regarding the socio-economic parameters (gender, religion, dependent and income) as well as their perception towards choice of occupation, migration and willingness to stay in same occupation.

\section{Design and procedure}

The data for Vijayawada was collected through the questionnaire in approximately two weeks. The data for Chennai was available from the previous study of the author published recently [5]. Post data collection from the field, path analysis was done to understand the impact of Gender (G), Religion (R) and Dependents (D) on Choice of Occupation (CoO), Choice of Migration (CoM), Distance of Migration (DoM) and Occupation before Migration (ObM). Later impact of all the above mentioned parameters was analysed on Willingness to Stay in Vending (WtS). Finally impact of G, R, D, CoO, CoM, DoM, ObM and WtS was analysed on Income (I) of vendors. 


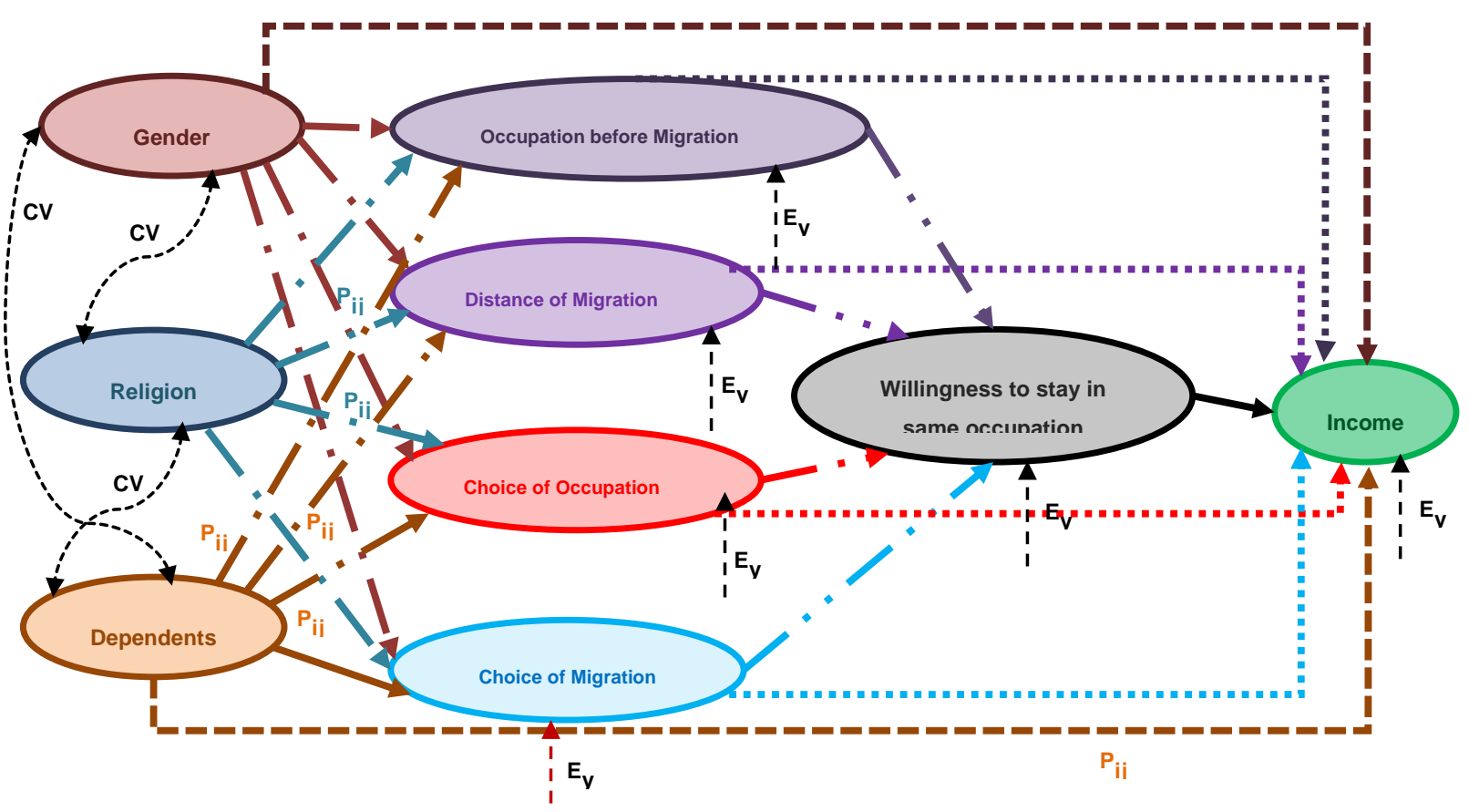

Fig. 3.Structural Equation Model

Source: Authors' work

In the diagram (Fig. 3), G, R and D are considered to be exogenous variables, that is, their variance is assumed to be caused entirely by variables not in the causal model.

The connecting line with arrows at both ends indicates that the correlation between these three variables will remain unanalyzed because we choose not to identify one variable as a cause of the other variable. Any correlation between these variables may actually be casual and/or may be due to these variables sharing common causes. For example, the co-variance between $\mathrm{G}, \mathrm{R}, \mathrm{D}$ is shown on the arrows.

$\mathrm{CoO}, \mathrm{CoM}, \mathrm{DoM}, \mathrm{ObM}$ and WtSand I are endogenous variables in this model - their variance is considered to be explained in part by other variables in the model. Paths drawn to endogenous variables are directional (arrowhead on one end only).

Variance in $\mathrm{CoO}, \mathrm{CoM}, \mathrm{DoM}, \mathrm{ObM}$ and $\mathrm{WtS}$ are theorized to result from variance in $\mathrm{G}, \mathrm{R}, \mathrm{D}$ and extraneous (not in the model) sources. The influence of these extraneous variables is indicated by the arrow labelled Ey. Variance in income is theorized to be caused by variance in $\mathrm{G}, \mathrm{R}, \mathrm{D}, \mathrm{CoO}, \mathrm{CoM}, \mathrm{DoM}, \mathrm{ObM}, \mathrm{WtS}$ and extraneous sources.

For each path to an endogenous variable a path coefficient, pij, has been calculated, where "i" indicates the effect and " $\mathrm{j}$ " the cause. If we square a path coefficient we get the proportion of the affected variable's variable. The coefficient may be positive (increasing the causal variable causes increases in the dependent variable if all other causal variables are held constant) or negative (increasing causal variable decreases dependent variable).

\section{Ethics}

The ethical principles of scientific research have been followed. The data of research were not distorted. The data was analyzed and interpreted, avoiding any possible bias and prejudices, respecting objectivity. As for the conduct of the research, the purpose of research was explained to protect the human subjects, respecting their autonomy and privacy. 


\section{Results}

All the variables were coded and the path analysis was conducted as a hierarchical (sequential) multiple regression analysis. For each endogenous variable a multiple regression analysis was done predicting income (Y) from all other variables (G, R, D, CoO, CoM, DoM, ObM, WtS) which are hypothesized to have direct effects on Y. We do not include in this multiple regression any variables which are hypothesized to affect $\mathrm{Y}$ only indirectly (through one or more intervening variables). The beta weights from these multiple regressions are the path coefficients shown in the typical figures that are used to display the results of a path analysis.

Path co-efficient model for Besant Road is illustrated in Fig. 4, to which path coefficients have been computed.

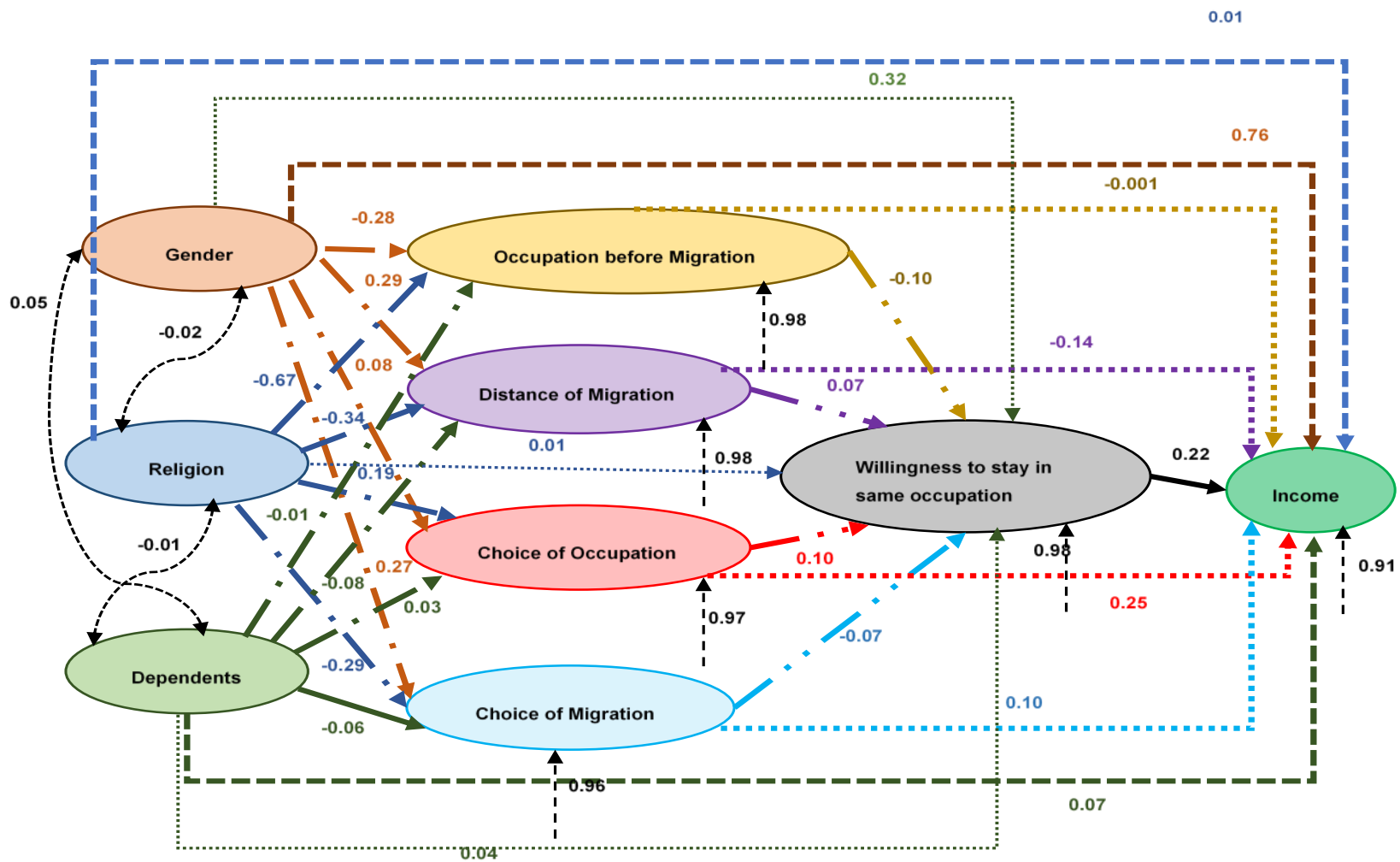

Fig. 4. Calibrated Structural Equation Model for Besant Road, Vijayawada

Calibration of path-coefficient is as follows:

Source: Authors'work

\section{Path co-efficient for gender on distance of migration}

Direct: 0.29

Unanalysed due to religion:

$-0.02 \mathrm{x}-0.34=0.007$

Unanalysed due to dependents:

$0.05 \mathrm{x}-0.08=-0.004$

Total $=0.29+0.007-0.004=\mathbf{0 . 2 9}$

Path co-efficient for religion on distance of migration

Direct: -0.34

Unanalysed due to gender:

$-0.02 \times 0.29=-0.006$

Unanalysed due to dependents:

$-0.01 \mathrm{x}-0.08=0.0008$

Total $=-0.34-0.006+0.0008=\mathbf{- 0 . 3 5}$

Path co-efficient for dependents on distance of migration

Direct: -0.08

Unanalysed due to gender: 
$0.05 \times 0.29=0.015$

Unanalysed due to religion:

$-0.01 \mathrm{x}-0.34=0.003$

Total $=-0.08+0.015+0.003=-\mathbf{0 . 0 6}$

Structural Equation for distance of migration

$-0.08+0.015-0.06+0.97=0.85$

Path co-efficient for gender on occupation before migration

Direct: -0.28

Unanalysed due to religion:

$-0.02 \mathrm{x}-0.67=0.013$

Unanalysed due to dependents:

$0.05 \mathrm{x}-0.01=-0.0005$

Total $=-0.28+0.013-0.0005=-0.27$

Path co-efficient for religion on occupation before migration

Direct: -0.67

Unanalysed due to gender:

$-0.02 \mathrm{x}-0.28=0.006$

Unanalysed due to dependents:

$0.05 \mathrm{x}-0.01=-0.0005$

Total $=-0.67+0.006-0.0005=\mathbf{- 0 . 6 6}$

Path co-efficient for dependents on occupation before migration

Direct: -0.01

Unanalysed due to gender:

$0.05 \mathrm{x}-0.28=-0.014$

Unanalysed due to religion:

$-0.01 \mathrm{x}-0.67=0.007$

Total $=-0.01-0.014+0.007=\mathbf{- 0 . 0 2}$

Structural Equation for occupation before migration

$-0.27-0.66-0.02+0.95=0.00$

Path co-efficient for gender on choice of occupation

Direct: 0.08

Unanalysed due to religion:

$-0.02 \times 0.19=-0.004$

Unanalysed due to dependents:

$0.05 \times 0.03=0.002$

Total $=0.08-0.004+0.002=0.08$

Path co-efficient for religion on choice of occupation

Direct: 0.19

Unanalysed due to gender:

$-0.02 \times 0.08=-0.002$

Unanalysed due to dependents:

$-0.01 \times 0.03=0.0003$

Total $=0.19-0.002+0.0003=0.19$

Path co-efficient for dependents on choice of occupation

Direct: 0.03

Unanalysed due to gender:

$0.05 \times 0.08=0.004$

Unanalysed due to religion:

$-0.01 \times 0.19=-0.002$

Total $=0.03+0.004-0.002=\mathbf{0 . 0 3}$

Structural Equation for choice of occupation

$0.08+0.19+0.03+0.99=1.29$

Path co-efficient for gender on choice of migration 
Direct: 0.27

Unanalysed due to religion:

$-0.02 \mathrm{x}-0.29=0.006$

Unanalysed due to dependents:

$0.05 \mathrm{x}-0.06=0.003$

Total $=0.27+0.006+0.003=0.28$

Path co-efficient for religion on choice of migration

Direct: -0.29

Unanalysed due to gender:

$-0.02 \times 0.27=-0.005$

Unanalysed due to dependents:

$-0.01 \mathrm{x}-0.06=0.0006$

Total $=-0.29-0.005+0.0006=\mathbf{- 0 . 2 9}$

Path co-efficient for dependents on choice of migration

Direct: -0.06

Unanalysed due to gender:

$0.05 \times 0.27=0.014$

Unanalysed due to religion:

$-0.01 \mathrm{x}-0.29=0.003$

Total $=-0.04-0.055+0.018=\mathbf{- 0 . 0 4}$

Structural Equation for choice of migration

$0.28-0.29-0.04+0.98=0.93$

Path co-efficient for gender on willingness to stay in same occupation

Direct: 0.32

Unanalysed due to religion:

$-0.02 \times 0.01=-0.0002$

Unanalysed due to dependents:

$0.05 \times 0.04=0.002$

Total $=0.32-0.0002+0.002=0.32$

Path co-efficient for religion on willingness to stay in same occupation

Direct: 0.01

Unanalysed due to gender:

$-0.02 \times 0.32=-0.006$

Unanalysed due to dependents:

$-0.01 \times 0.04=-0.0004$

Total $=0.01-0.006-0.0004=\mathbf{0 . 0 0 4}$

Path co-efficient for dependents on willingness to stay in same occupation

Direct: 0.04

Unanalysed due to gender:

$0.05 \times 0.32=0.016$

Unanalysed due to religion:

$-0.01 \times 0.01=-0.0001$

Total $=0.04+0.016-0.0001=\mathbf{0 . 0 6}$

Path co-efficient for occupation before migration on willingness to stay in same occupation

Direct: -0.10

Spurious:

Occupation before migration-Gender-willingness to stay in same occupation:

$-0.28 \times 0.32=-0.09$

Occupation before migration-Religion-willingness to stay in same occupation:

$-0.67 \times 0.01=-0.007$

Occupation before migration-Dependents-willingness to stay in same occupation:

$-0.01 \times 0.04=-0.0004$

Total: $-0.10-0.09-0.007-0.0004=\mathbf{- 0 . 2 0}$

Path co-efficient for distance of migration on willingness to stay in same occupation

Direct: 0.07 
Spurious:

Distance of migration-Gender-willingness to stay in same occupation:

$0.29 \times 0.32=0.093$

Distance of migration-Religion-willingness to stay in same occupation:

$-0.34 \times 0.01=-0.003$

Distance of migration-Dependents-willingness to stay in same occupation:

$-0.08 \times 0.04=0.0032$

Total: $0.07+0.093-0.003+0.0011=\mathbf{0 . 1 6}$

Path co-efficient for choice of occupation on willingness to stay in same occupation

Direct: 0.10

Spurious:

Choice of occupation-Gender-willingness to stay in same occupation:

$0.06 \times 0.32=0.02$

Choice of occupation-Religion-willingness to stay in same occupation:

$0.19 \times 0.01=0.002$

Choice of occupation-Dependents-willingness to stay in same occupation:

$0.03 \times 0.04=0.0012$

Total: $0.10+0.02+0.002+0.0012=\mathbf{0 . 1 2}$

Path co-efficient for choice of migration on willingness to stay in same occupation

Direct: -0.07

Spurious:

Choice of migration-Gender-willingness to stay in same occupation:

$0.27 \times 0.32=0.09$

Choice of migration-Religion-willingness to stay in same occupation:

$-0.29 \times 0.01=0.003$

Choice of migration-Dependents-willingness to stay in same occupation:

$-0.06 \times 0.04=-0.0024$

Total: $-0.07+0.09+0.003-0.0024=\mathbf{0 . 0 2}$

Structural Equation for willingness to stay in same occupation $0.32+0.004+0.06-0.20+0.16+0.12+0.02+0.99=0.81$

\section{Path co-efficient for gender on income}

Direct: 0.76

Unanalysed due to religion:

$-0.02 \times 0.01=-0.0002$

Unanalysed due to dependents:

$0.05 \times 0.07=0.004$

Total $=0.21-0.0002+0.004=0.21$

Path co-efficient for religion on income

Direct: 0.01

Unanalysed due to gender:

$-0.02 \times 0.76=-0.02$

Unanalysed due to dependents:

$-0.01 \times 0.07=-0.0007$

Total $=0.01-0.02-0.0007=\mathbf{- 0 . 0 1}$

Path co-efficient for dependents on income

Direct: 0.07

Unanalysed due to gender:

$0.05 \times 0.76=0.04$

Unanalysed due to religion:

$-0.01 \times 0.01=-0.0001$

Total $=0.07+0.04-0.0001=\mathbf{0 . 1 1}$

Path co-efficient for distance of migration on income

Direct: -0.14

Spurious: 
Distance of migration-Gender-willingness to stay in same occupation-income:

$0.29 \times 0.32 \times 0.22=0.02$

Distance of migration-Religion-willingness to stay in same occupation-income:

$-0.34 \mathrm{x} 0.01 \times 0.22=-0.0007$

Distance of migration-Dependents-willingness to stay in same occupation-income:

$-0.08 \times 0.04 \times 0.22=-0.0007$

Distance of migration-Gender-income:

$0.29 \times 0.76=0.22$

Distance of migration-Religion-income:

$-0.34 \times 0.01=-0.003$

Distance of migration-Dependents-income:

$-0.08 \times 0.04=-0.003$

Distance of migration- willingness to stay in same occupation-income:

$0.07 \times 0.22=0.015$

Total: $-0.14+0.02-0.0007-0.0007+0.22-0.003-0.003+0.015=0.11$

Path co-efficient for occupation before migration on income

Direct: -0.001

Spurious:

Occupation before migration-Gender-willingness to stay in same occupation-income:

$-0.28 \times 0.32 \times 0.22=-0.02$

Occupation before migration-Religion-willingness to stay in same occupation-income:

$-0.67 \times 0.01 \times 0.22=-0.001$

Occupation before migration-Dependents-willingness to stay in same occupation-income:

$-0.01 \times 0.04 \times 0.22=-0.00001$

Occupation before migration-Gender-income:

$-0.28 \times 0.76=-0.21$

Occupation before migration-Religion-income:

$-0.67 \times 0.01=-0.007$

Occupation before migration-Dependents-income:

$-0.01 \times 0.07=-0.0007$

Occupation before migration-willingness to stay in same occupation-income:

$-0.10 \times 0.22=-0.02$

Total: $-0.001-0.02-0.001-0.00001-0.21-0.007-0.0007-0.02=\mathbf{- 0 . 2 6}$

Path co-efficient for choice of occupation on income

Direct: 0.25

Spurious:

Choice of Occupation -Gender-willingness to stay in same occupation-income:

$0.08 \times 0.32 \times 0.22=0.006$

Choice of Occupation -Religion-willingness to stay in same occupation-income:

$0.19 \times 0.01 \times 0.22=0.0004$

Choice of Occupation -Dependents-willingness to stay in same occupation-income:

$0.03 \times 0.04 \times 0.22=0.0002$

Choice of Occupation -Gender-income:

$0.08 \times 0.76=0.06$

Choice of Occupation -Religion-income:

$0.19 \times 0.01=0.002$

Choice of Occupation -Dependents-income:

$0.03 \times 0.07=0.002$

Choice of Occupation -willingness to stay in same occupation-income:

$0.10 \times 0.22=0.02$

Total: $0.25+0.006+0.0004+0.0002+0.06+0.002+0.002+0.02=0.34$

Path co-efficient for choice of migration on income

Direct: 0.10

Spurious:

Choice of migration-Gender-willingness to stay in same occupation-income:

$0.27 \times 0.32 \times 0.22=0.02$ 
Choice of migration-Religion-willingness to stay in same occupation-income:

$-0.29 \times 0.01 \times 0.22=-0.0006$

Choice of migration-Dependents-willingness to stay in same occupation-income:

$-0.06 \times 0.04 \times 0.22=-0.0005$

Choice of migration-Gender-income:

$0.27 \times 0.76=0.21$

Choice of migration-Religion-income:

$-0.29 \times 0.01=-0.002$

Choice of migration-Dependents-income:

$-0.06 \times 0.07=-0.004$

Choice of migration-willingness to stay in same occupation-income:

$-0.07 \times 0.22=-0.02$

Total: $0.10+0.02-0.0006-0.0005+0.21-0.002-0.004-0.02=\mathbf{0 . 3 0}$

Path co-efficient for willingness to stay in same occupation on income

Direct: 0.22

Spurious:

Willingness to stay in same occupation-distance of migration-gender-income:

$0.07 \times 0.29 \times 0.76=0.02$

Willingness to stay in same occupation-distance of migration-religion-income:

$0.07 \mathrm{x}-0.34 \mathrm{x} 0.01=-0.0002$

Willingness to stay in same occupation-distance of migration-dependents-income:

$0.07 \mathrm{x}-0.08 \mathrm{x} 0.07=-0.0004$

Willingness to stay in same occupation-occupation before migration-gender-income:

$-0.10 \mathrm{x}-0.28 \mathrm{x} 0.76=0.02$

Willingness to stay in same occupation-occupation before migration-religion-income:

$-0.10 \mathrm{x}-0.67 \mathrm{x} 0.01=0.0007$

Willingness to stay in same occupation-occupation before migration-dependents-income:

$-0.10 \mathrm{x}-0.01 \mathrm{x} 0.07=0.00007$

Willingness to stay in same occupation-choice of occupation-gender-income:

$0.10 \times 0.08 \times 0.76=0.006$

Willingness to stay in same occupation-choice of occupation-religion-income:

$0.10 \times 0.19 \times 0.01=0.0002$

Willingness to stay in same occupation-choice of occupation-dependents-income:

$0.10 \times 0.03 \times 0.07=0.0002$

Willingness to stay in same occupation-choice of migration-gender-income:

$-0.07 \times 0.27 \times 0.76=-0.014$

Willingness to stay in same occupation-choice of migration-religion-income:

$-0.07 \mathrm{x}-0.29 \mathrm{x} 0.01=0.0002$

Willingness to stay in same occupation-choice of migration-dependents-income:

$-0.07 \mathrm{x}-0.06 \mathrm{x} 0.07=0.0003$

Willingness to stay in same occupation-gender-income:

$0.32 \times 0.76=0.24$

Willingness to stay in same occupation-religion-income:

$0.01 \times 0.01=0.0001$

Willingness to stay in same occupation-dependents-income:

$0.04 \times 0.07=0.003$

Total: $0.22+0.02-0.0002-0.0004+0.02+0.0007+0.00007+0.006+0.0002+0.0002-0.014+0.0002+0.0003+$ $0.24+0.0001+0.003=0.50$

Structural Equation for income

$0.21-0.01+0.11+0.11-0.26+0.34+0.30+0.50+0.91=2.21$ 
Updated calibrated SEM for Besant Road, Vjayawada and Pondy Bazar, Chennai have been depicted in Fig. 5 and Fig. 6.

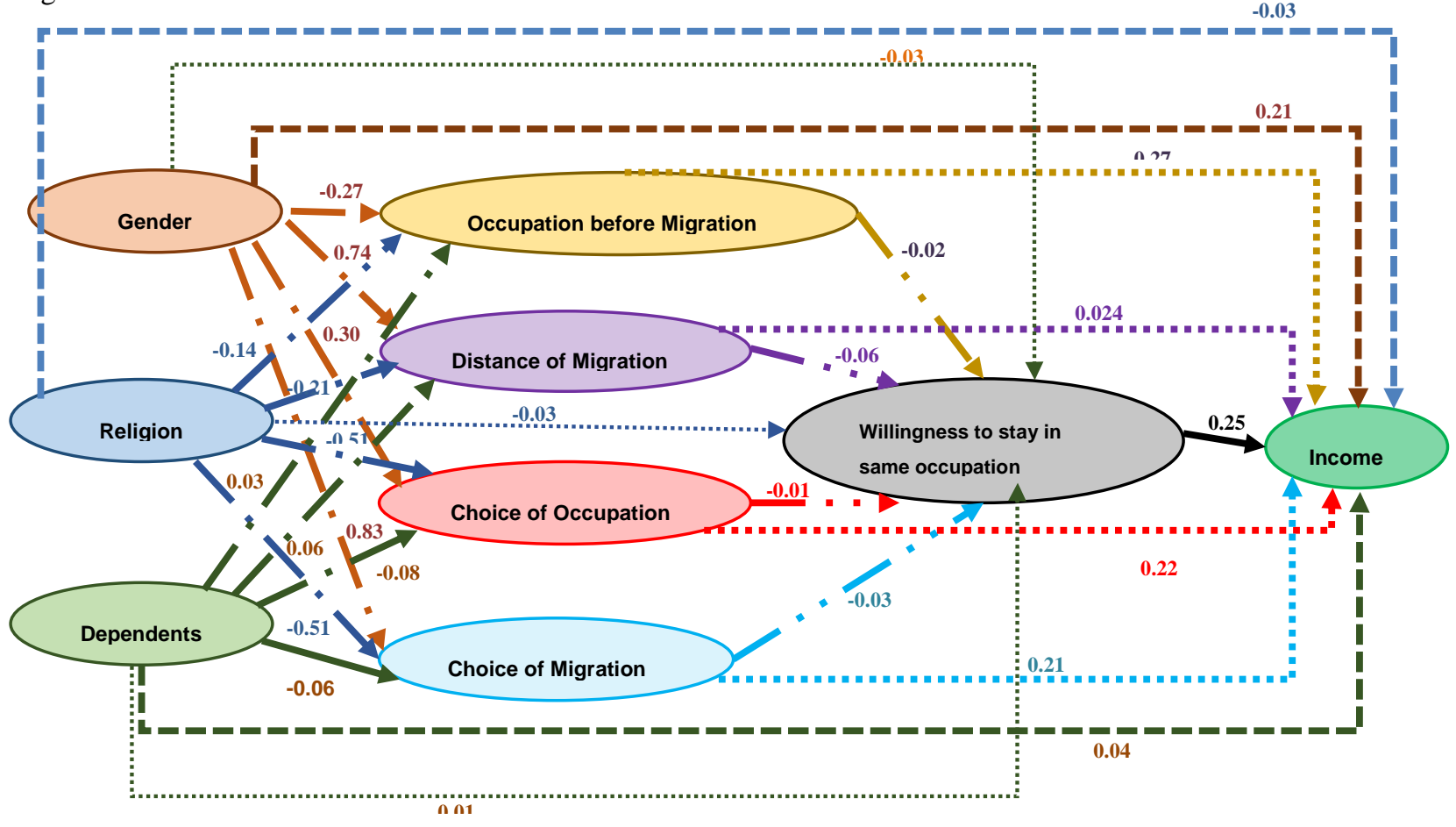

Fig. 5. Updated calibrated Structural Equation Model for Besant Road, Vijayawada

Source: Authors' work

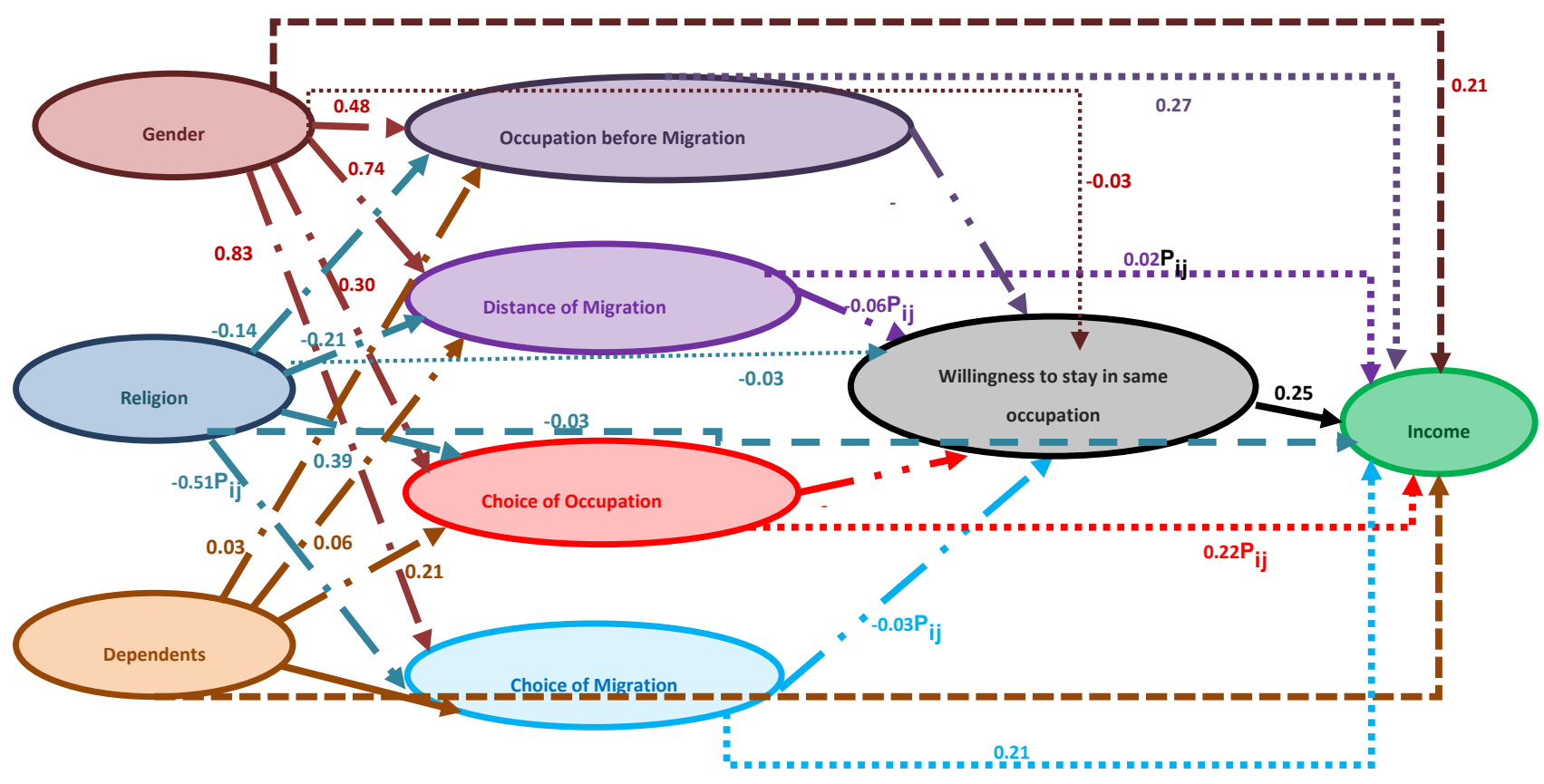

Fig. 6: Updated calibrated Structural Equation Model for Pondy Bazar, Chennai

Source: Sharma 2017 


\section{Discussion}

There are some really interesting points to note from the SEM models of the two cities (Fig. 5, Fig. 6). First, the structural equation for Income is the highest for both Chennai and Vijayawada. However, the co-efficient is lesser in case of Chennai than Vijayawada. The structural equation co-efficients are smaller in case of Vijayawada as compared to Chennai, for all the other parameters considered (Fig. 5). Second, for Vijayawada the co-efficient for structural equation is highest for income followed by CoO, CoM and DoM and WtS. What is most interesting is that the co-efficient structural equation for ObM is 0 (Table 1). Third, for Chennai the co-efficient is highest for highest for income followed by CoO, DoM, ObM, CoM and least for WtS (Table 1). Fourth, WtS co-efficient is same for both Chennai and Vijayawada.

\section{a) Deciphering SEM for Occupation before Migration (ObM)}

i. Gender (female, male), religion (Christian, Muslim, Hindu) and dependents all have negative relationship with ObM (not working, service, agriculture, business, vending). This means that more Christian females who had less or no dependents on them have been engaged in vending even before migrating and males were engaged in either service or agriculture prior to vending in case of Vijayawada.

ii. In Chennai only religion seems to be negatively related to ObM, that is, more Christians and Muslims are engaged in vending than Hindus.

iii. Religion seems to have the strongest (negative) relationship with ObM in Vijayawada implying that minority groups opted for vending in the past and still continue to do so while Hindus still prefer to engage in formal activities. Gender seems to have the strongest (positive) relationship with ObM in Chennai implying that more men have continued to be in vending than females.

iv. The number of dependents as a parameters of analysis has a very small impact on ObM in both the cities. However in Vijayawada, families with lesser dependents have continued to be in vending while in Chennai families with larger dependent population have continued to be in vending.

\section{b) Deciphering SEM for Distance of Migration (DoM)}

i. Gender has a positive relationship with DoMin case of Chennai (above $800 \mathrm{kms}, 600-800 \mathrm{kms}, 400-600 \mathrm{kms}$, 200-400 kms and 0-200 kms) as well as Vijayawada (above $2200 \mathrm{kms}, 1650-2200 \mathrm{kms}, 1100-1650 \mathrm{kms}, 550$ $1100 \mathrm{kms}$ and $0-550 \mathrm{kms}$ ). What is to be noted is that the migrants (males in both the cities) travel from even shorter distances to Chennai than Vijayawada. This implies that Vijayawada seems to be engaging and attracting more migrants to settle in informal sector than Chennai.

ii. Religion has negative relationship to distance of migration. This implies that the Christians and Muslims travel over shorter distances than their Hindu counterparts in both the cities.

iii. The families having less dependents are free to travel large distances in case of Vijayawada while in Chennai, more the dependents, larger distances vendors are ready to travel to set up their business. In Chennai, the families having larger number of dependents around Chennai city prefer to send one of the family members to earn in the city. Since the distance from which people migrate to Vijayawada is much larger, thus families with lager number of dependents do not prefer to travel long distances to settle in informal sector.

\section{c) Deciphering SEM for Choice of Occupation (CoO)}

i. All the three parameters; vizgender, religion and dependents have positive relationship with CoO (society pressure, family pressure, family business, own choice) in both the cities. This implies that more males have opted for vending of their own choice while females had to resort to vending due to either societal or family pressure. Similarly, Christians and Muslims opted for vending under some pressure from society or family, unlike the Hindus who opted for vending due to their own will. Families with smaller number of dependents thought it more profitable to settle in vending than going for other formal jobs.

ii. The impact of gender, religion and dependents are much stronger in case of Chennai than in case of Vijayawada. This means that as the size of the city increases, these factors accentuate with regard to CoO. 
d) Deciphering SEM for Choice of Migration (CoM)

i. Gender has positive impact on $\mathrm{CoM}$ (pressure from acquaintance, pressure from relatives, pressure from family members and own choice) in both the cities alike. This means that male vendors have decided to migrate due to thir own free will while females have migrated under some pressure either the relatives or acquaintances. The main reason for this could be marriage.

ii. Religion and dependents have negative relationship with CoM in both the cities. More Hindus have migrated based on some reference from relatives or acquaintance while Muslims and Christians migrated of their own accord in both the cities. Families with more dependents had less choice to opt for migration while families with less dependents gave more choice to vendors to migrate from one place to another.

iii. While gender and religion have an almost same effect on CoM in case of Vijayawada, gender seems to be more dominant in case of Chennai. This implies that males have a strong preference to opt for migration on their own free will in Chennai while in case of Vijayawada, Christian or Muslim male vendors have strong preference to migrate as per their choice than their Hindu counterparts.

e) Deciphering SEM for Willingness to Stay (WtS)

i. Structural equation model co-efficient for $\mathrm{WtS}$ is same for both the cities.

ii. Except $O b M$, all parameters have a positive co-efficient with respect to $\mathrm{WtS}$ in the city of Vijayawada. This means that people who are engaged were engaged in vending for a long time (even before migration) do not want to stay in this occupation. However, the people who were engaged either in agriculture or not employed earlier are willing to continue in vending in future as well.

iii. Hindu males coming from families having large dependent population, who have migrated from large distances of their own free will and opted for vending out of their own choice are willing to continue vending in Vijayawada considering its costs and benefits.

iv. Except dependents, all parameters have a negative co-efficient with respect to $\mathrm{WtS}$ in the city of Chennai. The vendors belonging to families which have large dependent population in Chennai are willing to continue in the same occupation as opposed to vendors having less dependent population to feed in their family.

v. Christian or Muslim females who migrated from shorter distances (nearby Chennai city), either engaged in agriculture or not working before migration, chose to migrate due to family pressure and chose vending due to societal or family pressure are willing to continue vending considering its benefits than shifting to formal sector.

\section{f) Deciphering SEM for Income}

i. SEM co-efficient for income is higher for Vijayawada than Chennai. This implies that the socio-cultural factors have more impact on the metro city (Vijayawada) than the mega city (Chennai).

ii. Except religion all parameters have a positive relationship with income in Vijayawada. Religion has a negative relationship with income even in case of Chennai. Earnings of Hindus are lesser than their Muslim or Christian counterparts engaged in the same occupation.

iii. Christian/ Muslim male vendors coming from families with small dependent population who have been engaged in vending for a long time (even before migration) migrating from shorter distances on their own free and who chose vending as their preferred choice earn more in Vijayawada.

iv. $O b M$ is an additional parameter which has a negative relationship with income in case of Chennai. The people who have been employed in vending for a long duration of time (even before migration) have lower incomes than people who were engaged in either agriculture, not employed or employed in some other business. This is probably due to innovative ways of vending by the starters than their counterparts.

v. Christian/ Muslim male vendors coming from families having small dependent population who were not in vending earlier, migrating from shorter distances on their own free will and who chose vending as their preferred choice earn more in Chennai. 
IRA-International Journal of Management E' Social Sciences

Table 1. Comparison between Vijayawada and Chennai of Path Co-efficient for parameters

\begin{tabular}{|c|c|c|}
\hline Variables & Vijayawada Path Co-eff & Chennai Path Co-eff \\
\hline \multicolumn{3}{|c|}{ Occupation before Migration (ObM) } \\
\hline Gender on ObM & -0.27 & 0.48 \\
\hline Religion on ObM & -0.66 & -0.14 \\
\hline Dependents on ObM & -0.02 & 0.03 \\
\hline Structural equation for ObM & 0.00 & 1.35 \\
\hline \multicolumn{3}{|c|}{ Distance of Migration (DoM) } \\
\hline Gender on DoM & 0.29 & 0.74 \\
\hline Religion on DoM & -0.35 & -0.21 \\
\hline Dependents on DoM & -0.06 & 0.06 \\
\hline Structural equation for DoM & 0.85 & 1.57 \\
\hline \multicolumn{3}{|c|}{ Choice of Occupation (CoO) } \\
\hline Gender on $\mathrm{CoO}$ & 0.08 & 0.30 \\
\hline Religion on $\mathrm{CoO}$ & 0.19 & 0.39 \\
\hline Dependents on $\mathrm{CoO}$ & 0.03 & 0.21 \\
\hline Structural equation for $\mathrm{CoO}$ & 1.29 & 1.88 \\
\hline \multicolumn{3}{|c|}{ Choice of Migration (CoM) } \\
\hline Gender on CoM & 0.28 & 0.83 \\
\hline Religion on CoM & -0.29 & -0.51 \\
\hline Dependents on CoM & -0.04 & -0.08 \\
\hline Structural equation for CoM & 0.93 & 1.20 \\
\hline \multicolumn{3}{|c|}{ Willingness to Stay (WtS) in the same occupation } \\
\hline Gender on WtS & 0.32 & -0.03 \\
\hline Religion on WtS & 0.004 & -0.03 \\
\hline Dependents on WtS & 0.06 & 0.01 \\
\hline $\mathrm{ObM}$ on WtS & -0.20 & -0.02 \\
\hline DoM on WtS & 0.16 & -0.06 \\
\hline $\mathrm{CoO}$ on WtS & 0.12 & -0.01 \\
\hline CoM on WtS & 0.02 & -0.03 \\
\hline Structural equation for WtS & 0.81 & 0.81 \\
\hline \multicolumn{3}{|c|}{ Income } \\
\hline Gender on Income & 0.21 & 0.21 \\
\hline Religion on Income & -0.03 & -0.01 \\
\hline Dependents on Income & 0.04 & 0.11 \\
\hline ObM on Income & 0.27 & -0.26 \\
\hline DoM on Income & 0.024 & 0.11 \\
\hline $\mathrm{CoO}$ on Income & 0.22 & 0.34 \\
\hline CoM on Income & 0.21 & 0.30 \\
\hline WtS on Income & 0.50 & 0.50 \\
\hline Structural equation for Income & 2.28 & 2.21 \\
\hline
\end{tabular}

\section{Conclusion}

As the size of the city increases, geographical and economic factors become more important than the social or cyclical factors. In smaller size cities, the social and geographical factors are more than cyclical factors while economic factors don't seem to be important at all with regard to vending activities.

However, when the impact of these parameters is seen on income, then cyclical and economic factors have a major impact on incomes of vendors rather than social factors in Vijayawada. Geographical factors seem to be least important when seen in relation to their impact on income of vendors. Although vendors coming from shorter distances earn more, yet it has a minor impact on earnings of vendors.

In case of Chennai, the cyclical, few social (gender, $\mathrm{CoO}$ and $\mathrm{CoM}$ ) and economic factors are more important in impacting income of vendors than geographical and other social factors (DoM, dependents and religion). 


\section{Acknowledgement}

The author would like to acknowledge the street vendors of Pondy Bazar, Chennai and Besant Road, Vijayawada who participated enthusiastically in the research.

\section{References}

[1]. Bradshaw, T. K. (2000). Complex Community Development Projects: Collaboration, Comprehensive Programs and Community Coalitions in Complex Society. Community Development Journal, Vol. 35, Issue 2, 133-145.

[2]. Lewis, 0. (1968). The Culture of Poverty. New York: Random House Inc.

[3]. Myrdal, G. (1957). Economic Theory and Underdeveloped Regions. London: Gerald Duckworth and Co.

[4]. Sharma, S. (2017). Individual Theory of Poverty and Informal Sector: Linkages or Alternative Explanations. International Journal of Advanced Research. Vol. 5, Issue 10, 1356-1363.

[5]. Sharma, S. (2018). Cultural Theory of Poverty and Informal Sector: A Case Study of Street Vendors of Pondy Bazaar, Chennai. Research Journal of Humanities and Social Sciences, Vol. 9, Issue 3, 557-566. 